Original Research Paper

\title{
Responses of Milling Quality to Nitrogen and Water Management in Modern Long Grain Rice Varieties
}

\author{
${ }^{1}$ Thitinan Sreethong, ${ }^{2}$ Benjavan Rerkasem, ${ }^{3}$ Bernard Dell, ${ }^{1}$ Sansanee Jamjod and ${ }^{1}$ Chanakan Prom-u-Thai \\ ${ }^{1}$ Agronomy Division, Department of Plant and Soil Sciences, \\ Faculty of Agriculture, Chiang Mai University, Chiang Mai 50200, Thailand \\ ${ }^{2}$ Plant Genetic Resource and Nutrition Laboratory, Chiang Mai University, Chiang Mai 50200, Thailand \\ ${ }^{3}$ Agricultural Sciences, Murdoch University, Perth 6150, Australia
}

\author{
Article history \\ Received: 24-08-2019 \\ Revised: 01-10-2019 \\ Accepted: 10-10-2019 \\ Corresponding Author: \\ Chanakan Prom-u-Thai \\ Agronomy Division, \\ Department of Plant and Soil \\ Sciences, Faculty of \\ Agriculture, Chiang Mai \\ University, Chiang Mai 50200, \\ Thailand \\ Email: chanakan15@hotmail.com \\ chanakan.p@cmu.ac.th
}

\begin{abstract}
This study determined how nitrogen (N) fertilizer and water management affect grain yield and milling quality of 9 modern rice varieties with long, slender grain in two field experiments. The effect of $\mathrm{N}$ on rice grown in wetland culture was evaluated at 0,60 and $120 \mathrm{~kg} \mathrm{~N} \mathrm{ha}^{-1}$. In a second experiment the rice in aerobic and wetland culture were compared. The rice in both experiments were grown to maturity and evaluated for yield, head rice yield and chalkiness. Grain yield increased with increasing $\mathrm{N}$ application, head rice yield increased with increasing $\mathrm{N}$ in 8 varieties, while chalkiness was more than halved in 7 varieties. Grain $\mathrm{N}$ also increased with increasing $\mathrm{N}$ fertilizer, but high head rice yield in several varieties was associated with relatively low grain $\mathrm{N}$. Under aerobic cultivation, all 9 varieties yielded less than in wetland culture, the head rice yield was lower and chalkiness was higher except in 2 varieties. In both experiments, grain yield was associated positively with head rice yield and negatively with chalkiness. Head rice yield and chalkiness were negatively associated in the water experiment but not in the $\mathrm{N}$ experiment. This study has shown that modern high yielding rice varieties generally respond positively to nitrogen fertilizer in better milling quality as well as in yield. Grain chalkiness of the varieties was more stable against variation in the environment than head rice yield.
\end{abstract}

Keywords: Nitrogen, Aerobic Soil, Wetland Culture, Head Rice Yield, Chalkiness

\section{Introduction}

Milled rice or white rice, the form commonly preferred by consumers, is processed by removal of the paddy rice hull, followed by polishing or milling process to remove the bran and germ fractions. Milled rice quality is judged based on several grain characteristics including head rice yield, grain chalkiness and contamination (Leesawatwong et al., 2003). Premium milling quality rice, which receives a higher price, is generally characterized by high percentage of unbroken grain and freedom from blemishes such as chalkiness (Efferson, 1985).

Milling quality is a complex trait which is influenced by both genetic and environmental factors (Zhao and Fitzgerald, 2013; Laenoi et al., 2018). Variety difference in milling quality has been documented with wide ranges of head rice yield, e.g., 8-69\% in indica rice varieties and $15-70 \%$ in japonica rice varieties, while grain chalkiness varied more widely in japonica rice at $1-100 \%$ than indica rice at 4-38\% (Koutroubas et al., 2004). Among 25 Indian local rice varieties, the head rice yield was reported to range from $45-73 \%$ and chalkiness from $10-100 \%$ (Bhonsle and Sellappan, 2010). In addition, variations in head rice yield and chalkiness were found to be $29-62 \%$ and $5-80 \%$, respectively, in 39 rice varieties developed by IRRI (Zhao and Fitzgerald, 2013). While opportunities to select for rice varieties with high head rice yield and low chalkiness are thus indicated, there is also the genotype $\times$ environment effect on rice grain quality to be considered.

Nitrogen fertilizer, a routine input in the cultivation of modern, high yielding rice varieties (Yoshida, 1981), has been reported to influence grain yield and milling quality (Perez et al., 1996; Wang et al., 2012). Application of $\mathrm{N}$ fertilizer improved milling quality by increasing head rice yield in some varieties but not in others (Borrell et al., 1999; Leesawatwong et al., 2005). Meanwhile, effects of $\mathrm{N}$ fertilizer on chalkiness have been reported in previous 
studies, but the findings differ. Borrell et al. (1999) reported that an increase in $\mathrm{N}$ fertilizer reduced chalkiness in one variety (Newbonnet) but not in two others (Starbonnet and Lemont). In contrast, a recent study documented that grain chalkiness increased in NJ9108 and NJ5055 rice varieties with an increase in N fertilizer (Zhu et al., 2017).

Water is another input that is crucial for high yield in modern rice varieties and the growing global water scarcity makes it necessary to use water more economically in rice production, one of the largest consumers of water especially in Asia (FAO, 2012). Aerobic rice cultivation, growing rice in well-drained instead of flooded soil, has been proposed as a means to increase water use efficiency (Bouman et al., 2005; Peng et al., 2006) as well as reducing greenhouse gas emission (Sharma et al., 2016) from rice production. A number of water management studies have reported on rice milling quality (e.g., Zhang et al., 2008; Hayashi et al., 2011), but not with aerobic rice. This study therefore aimed to evaluate how different rice varieties respond to $\mathrm{N}$ fertilizer and water management in milling quality as well as grain yield.

\section{Materials and Methods}

\section{Plant Materials}

Nine high yielding, photoperiod-insensitive wetland rice varieties were grown in two experiments, conducted concurrently in the dry season of 2011 at Chiang Mai University $\left(18.8060^{\circ} \mathrm{N}, 98.9534^{\circ} \mathrm{E}\right)$. The rice varieties all belong to the extra long and long, slender grain type, with high amylose (26.3-29.8\%), except RD21 and PTT1 (15.0-20.0\%) which are considered low amylose types (Table 1). One-month old seedlings of each variety were transplanted with $0.25 \times 0.25 \mathrm{~m}$ spacing between hills with a single seedling per hill. Basal fertilizer was applied at the rate of $30 \mathrm{~kg} \mathrm{P}_{2} \mathrm{O}_{5} \mathrm{ha}^{-1}$ and $30 \mathrm{~kg} \mathrm{~K}_{2} \mathrm{O} \mathrm{ha}{ }^{-1}$, half at tillering and half at flowering stage. At maturity, a $2 \mathrm{~m}^{2}$ sample was harvested manually from the internal area of each plot. The paddy rice was threshed by hand, cleaned and air dried to $14 \%$ moisture content prior to determination of yield and milling quality.

\section{Experiment 1: Effect of $N$ Fertilizer}

The experiment was laid out in a split plot design, with $\mathrm{N}$ rates of 0,60 and $120 \mathrm{~kg} \mathrm{~N} \mathrm{ha}^{-1}$ as main plots and cultivars in $2 \times 2.5 \mathrm{~m}$ subplots, in three replicated blocks. The rice was grown in a wetland culture, in a field that had been puddled and kept flooded to $5-10 \mathrm{~cm}$ above soil surface from transplanting until maturity. Half of the $\mathrm{N}$ was applied at tillering and half at flowering.

\section{Experiment 2: Effect of Water Management}

The experiment was laid out in a split plot design, with 2 water treatments, aerobic (W0) and wetland $(\mathrm{W}+)$ in main-plots and varieties in subplots, in three replicated blocks. There were $3 \mathrm{~m}$ wide strips of partition separating the aerobic and wetland blocks. The aerobic plots were dry ploughed and harrowed. The soil was soaked for $24 \mathrm{~h}$ before transplanting. After transplanting, seedling establishment was ensured by keeping the soil saturated for one week, after that the rice was sprinkler irrigated for approximately $3 \mathrm{~h}$ once a week. The wetland treatment was managed in the same way as experiment 1 . Nitrogen was applied by hand as urea at the rate of $60 \mathrm{~kg} \mathrm{~N} \mathrm{ha}^{-1}$, half at tillering and half at flowering.

\section{Grain Milling Quality and Chemical Analysis}

One hundred $\mathrm{g}$ sub-samples of the paddy rice were dehulled in a sampled huller (Ngek Seng Huat, model P-1) to yield brown rice and milled for $30 \mathrm{~s}$ in a laboratory milling machine (Ngek Seng Huat, model K1) to produce milled or white rice. A subsample of 15 grams of milled rice from each sample was separated into head rice ( $\geq 3 / 4$ length of whole milled grain) and broken rice. Head rice yield was expressed as the weight of head rice as percentage of the paddy weight. Grain chalkiness is defined as visually detectable opaque regions in an otherwise translucent background of a white rice grain and expressed as the number of grains in 100 randomly selected head rice grains with chalky area of more than half of the kernel.

Table 1: Rice varieties used to determine yield and milling quality

\begin{tabular}{lllllll}
\hline Variety & Length & Width & Length/width & Grain size & Grain shape & Amylose $(\%)$ \\
\hline SPR3 & 7.5 & 2.1 & 3.6 & Long & Slender & 28.3 \\
RD41 & 7.7 & 2.2 & 3.5 & Extra long & Slender & 27.2 \\
PSL2 & 7.9 & 2.1 & 3.8 & Extra long & Slender & 28.6 \\
RD21 & 7.3 & 2.3 & 3.2 & Long & Slender & $17.0-20.0$ \\
RD29 & 7.3 & 2.2 & 3.3 & Long & Slender & $26.6-29.4$ \\
CNT1 & 7.7 & 2.1 & 3.7 & Extra long & Slender & 26.3 \\
RD31 & 7.4 & 2.1 & 3.5 & Long & Slender & $27.3-29.8$ \\
SPR1 & 7.3 & 2.2 & 3.3 & Long & Slender & 29.0 \\
PTT1 & 7.6 & 2.1 & 3.6 & Extra long & Slender & $15.0-19.0$ \\
\hline
\end{tabular}

Note: Brown rice size categorized based on grain length: $>7.50 \mathrm{~mm}=$ extra long; 6.61-7.50 mm = long; 5.51-6.60 mm = medium. Grain shape categorized based on length-to-width ratio: $>3.0=$ slender; 2.1-3.0 = medium; 1.1-2.0 = bold (Juliano, 1993). 
Nitrogen concentration of the white rice in experiment 1 was analyzed by titration after Kjeldahl digestion (Yoshida et al., 1976).

\section{Statistical analysis}

Data of head rice yield and chalkiness were arcsine transformed before analysis of variance (ANOVA) using STATISTIX 8.0 (Analytical software, SXW). The least significant difference (LSD) at $\mathrm{p}<0.05$ was used for comparison between treatment mean. Correlation analysis between each parameter was performed by Pearson correlation analysis.

\section{Results}

\section{Effect of $N$ Rates on Yield and Milling Quality (Experiment 1)}

The interaction effect between variety and $\mathrm{N}$ rate was found to be significant on grain yield $(p<0.05)$ and highly significant $(\mathrm{p}<0.001)$ on milling quality and grain $\mathrm{N}$ concentration (Table 2). Without $\mathrm{N}$ fertilizer, the rice yield ranged from 5.28 to $6.25 \mathrm{t} \mathrm{ha}^{-1}$ (Fig. 1). Nitrogen fertilizer increased the grain yield in all rice varieties but to different extent. The varieties were classed according to their yield response to $\mathrm{N}$ into: (a) Those with the yield increasing progressively with $\mathrm{N}$ rate (SPR3, CNT1, SPR1, PTT1); (b) those with significant yield increase with $120 \mathrm{~kg} \mathrm{~N} \mathrm{ha}^{-1}$ (RD41, RD31); and (c) those with significant yield increase with $60 \mathrm{~kg} \mathrm{~N}^{-1}$ (PSL2, RD21, RD29).

Head rice yield increased progressively with increasing $\mathrm{N}$ to $120 \mathrm{~kg} \mathrm{~N} \mathrm{ha}^{-1}$, in 6 of the 9 rice varieties (Fig. 2a). The exceptions were SPR3 which was unresponsive to $\mathrm{N}$ and RD41, PSL2 which showed a significant increase in head rice yield only with $120 \mathrm{~kg} \mathrm{~N}$ ha $^{-1}$ but not at $60 \mathrm{~kg} \mathrm{~N} \mathrm{ha}^{-1}$. Without $\mathrm{N}$ fertilizer the head rice yield of the rice varieties ranged from 37.5 to $47.5 \%$, except in CNT1 which was especially low at $21.7 \%$. Head rice yield in CNT1 was increased to within the same range as 5 other varieties at 60 and $120 \mathrm{~kg} \mathrm{~N} \mathrm{ha}^{-1}$.

Table 2: $\mathrm{F}$ value of analysis of variance (ANOVA) for yield, head rice yield, chalkiness and nitrogen concentration of nine rice varieties grown at different $\mathrm{N}$ rates (Experiment 1) and water managements (Experiment 2)

\begin{tabular}{|c|c|c|c|c|}
\hline & Yield $\left(\mathrm{t} \mathrm{ha}^{-1}\right)$ & Head rice yield (\%) & Chalkiness (\%) & Nitrogen $(\%)$ \\
\hline \multicolumn{5}{|l|}{ Experiment 1} \\
\hline Nitrogen $(\mathrm{N})$ & $49.93 * *$ & $84.46^{* * *}$ & $266.00 * * *$ & $3079.81 * * *$ \\
\hline Variety (V) & $10.79 * * *$ & $26.93 * * *$ & $65.72 * * *$ & $54.71 * * *$ \\
\hline $\mathrm{N} \times \mathrm{V}$ & $2.12 *$ & $17.37 * * *$ & $6.43 * * *$ & $27.54 * * *$ \\
\hline \multicolumn{5}{|l|}{ Experiment 2} \\
\hline Water $(\mathrm{W})$ & $523.06 * *$ & $73.24^{*}$ & $874.88 * *$ & \\
\hline Variety (V) & $16.45 * * *$ & $11.80 * * *$ & $119.13 * * *$ & \\
\hline $\mathrm{W} \times \mathrm{V}$ & $1.77 \mathrm{~ns}$ & $4.04 * *$ & $9.12 * * *$ & \\
\hline
\end{tabular}

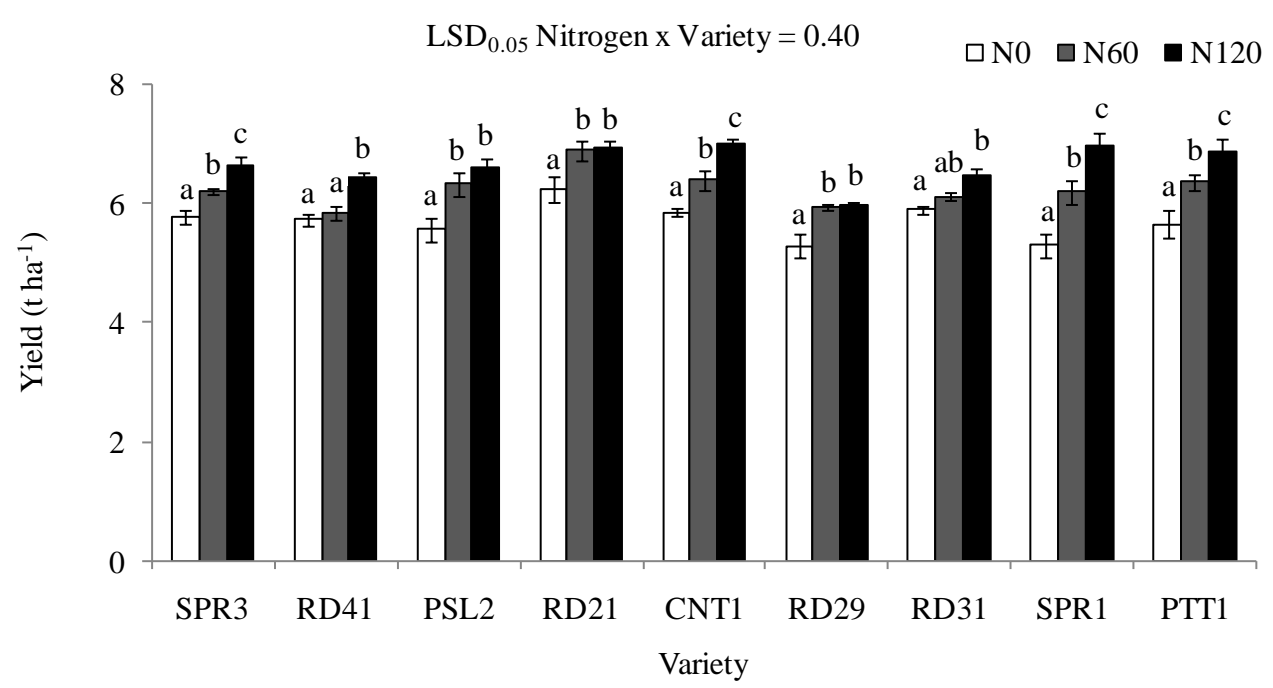

Fig. 1: Grain yield of nine rice varieties under $\mathrm{N}$ rate at 0,60 and $120 \mathrm{~kg} \mathrm{~N} \mathrm{ha}^{-1}$. Bars represent standard error of mean. Letters above bars represent significant difference between means of different $\mathrm{N}$ rates by LSD at $\mathrm{p}<0.05$ of nitrogen by variety. 
Without $\mathrm{N}$ fertilizer the rice varieties were classed as low chalkiness (5.7-11.7\%: PSL2, RD21, CNT1, RD29), moderate chalkiness (15.3-19.3\%: SPR3, RD41) and high chalkiness (27.3-35.0\%: RD31, SPR1, PTT1), with the least chalkiness at $60 \mathrm{~kg} \mathrm{~N} \mathrm{ha}^{-1}$ in 7 out of 9 varieties (Fig. 2b). The exceptions were PSL2 from the low chalkiness group and SPR3 from the moderate chalkiness group, in which there was no significant effect of $\mathrm{N}$ on grain chalkiness. Increasing $\mathrm{N}$ to $120 \mathrm{~kg} \mathrm{~N}$ $\mathrm{ha}^{-1}$ had little to no additional effect on the grain chalkiness. Thus $\mathrm{N}$ fertilizer appeared to have little effect on the ranking of rice varieties by their grain chalkiness.

Grain $\mathrm{N}$ concentration increased progressively with increasing rate of $\mathrm{N}$ fertilizer in all rice cultivars, except SPR3 and PSL2 (Fig. 2c). Grain N was significantly increased in SPR3 only at $60 \mathrm{~kg} \mathrm{~N} \mathrm{ha}^{-1}$ and in PSL2 at $120 \mathrm{~kg} \mathrm{~N} \mathrm{ha}^{-1}$. Nitrogen concentration of the rice grain was associated positively with head rice yield $(\mathrm{r}=$ $0.573, \mathrm{p}<0.01)$ and negatively with grain chalkiness $(\mathrm{r}=$ $-0.494, \mathrm{p}<0.01)($ Table 3).
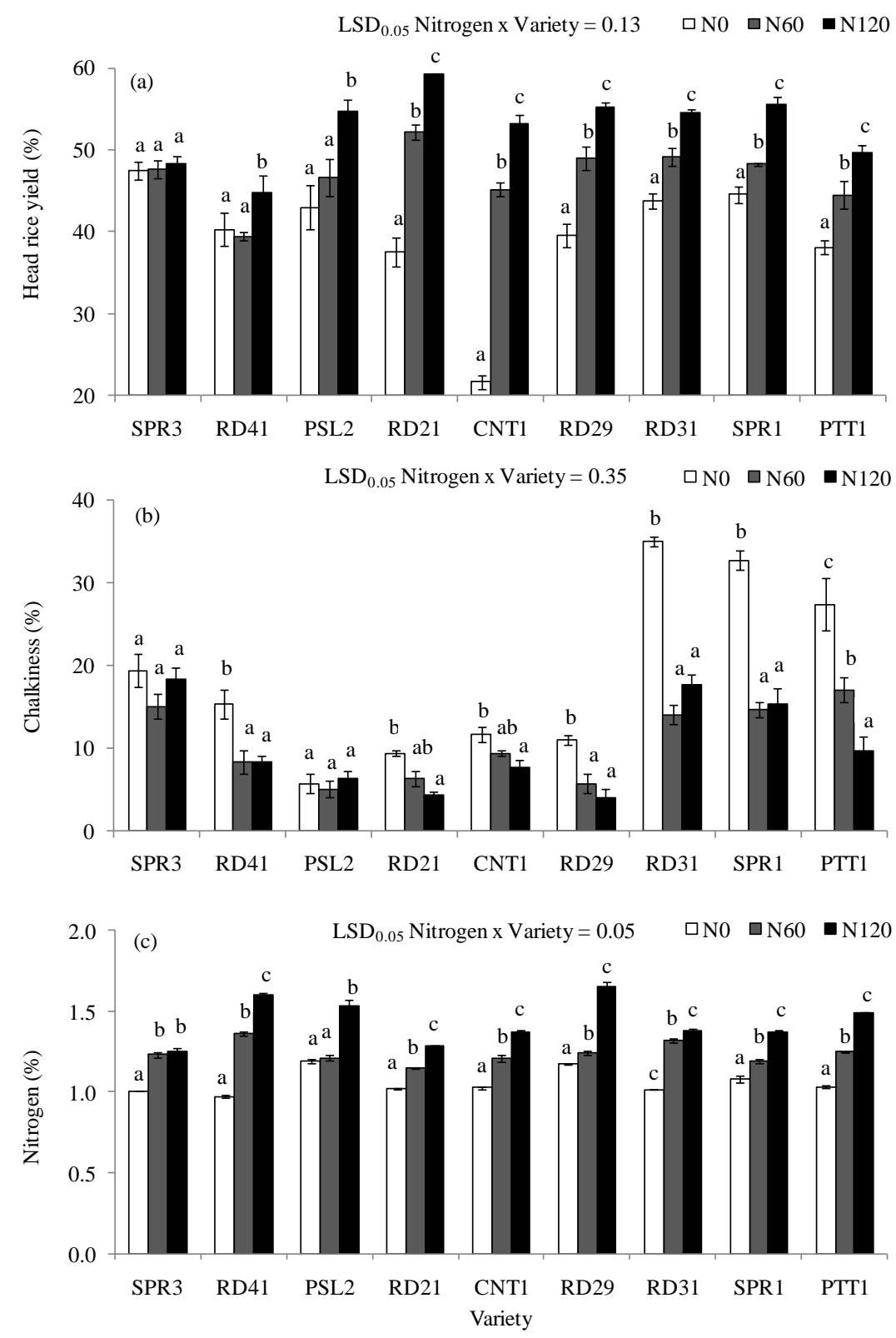

Fig. 2: Head rice yield (a), chalkiness (b) and nitrogen concentration (c) of nine rice varieties under $\mathrm{N}$ rate at 0,60 and $120 \mathrm{~kg} \mathrm{~N}$ $\mathrm{ha}^{-1}$. Bars represent standard error of mean. Letters above bars represent significant difference between mean of different $\mathrm{N}$ rates by LSD at $\mathrm{p}<0.05$ of nitrogen by variety. An arcsine transformation was performed before analysis by ANOVA 


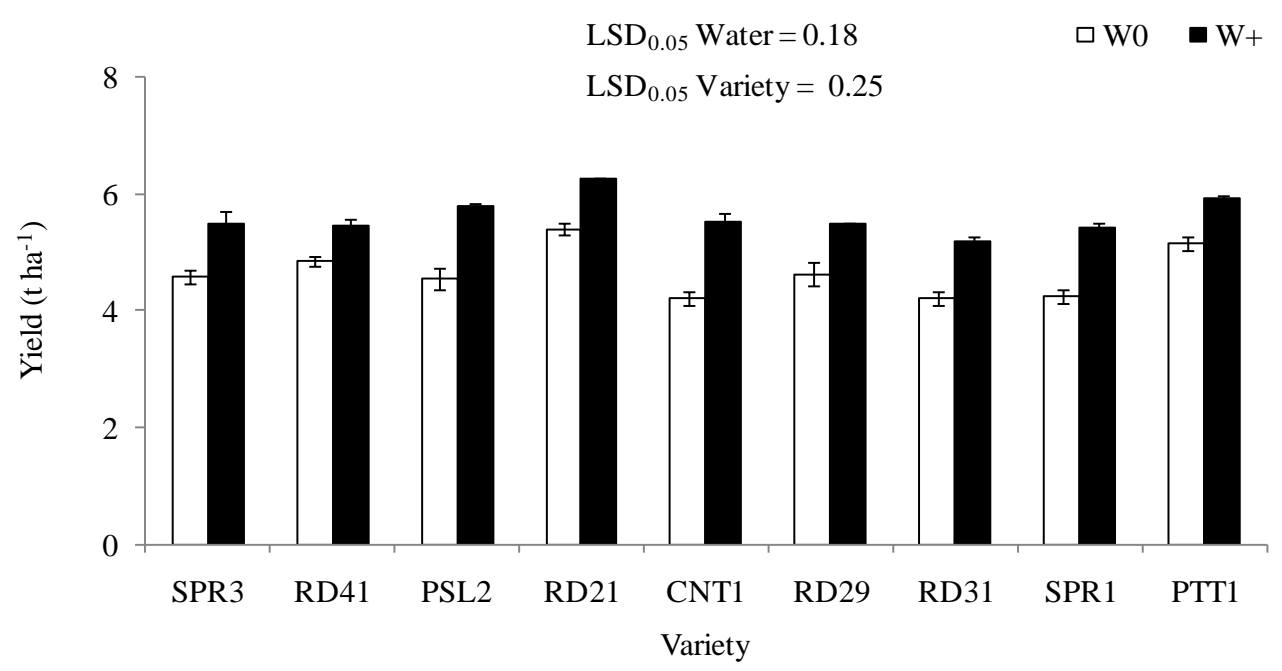

Fig. 3: Grain yield of nine rice varieties grown under aerobic (W0) and wetland (W+) culture. Bars represent standard error of mean
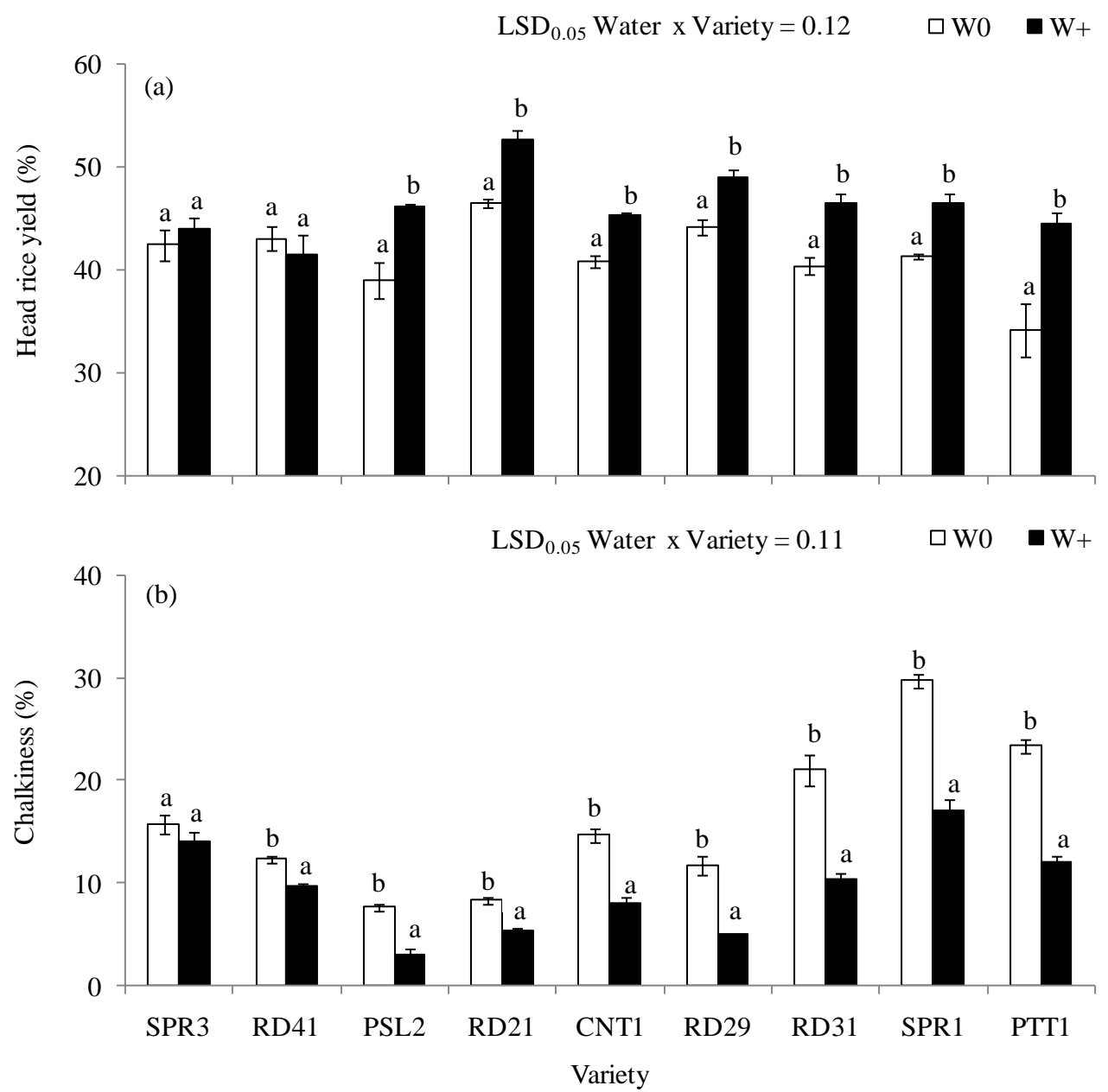

Fig. 4: Head rice yield (a) and chalkiness (b) of nine rice varieties under aerobic (W0) and wetland (W+). Bars represent standard error of mean. Letters above bars represent significant difference between means of different water treatments by LSD at $\mathrm{p}<0.05$ of water management by variety. An arcsine transformation was performed before analysis by ANOVA 
Table 3: Correlation analysis of yield, head rice yield, chalkiness and $\mathrm{N}$ concentration of nine rice varieties grown at different $\mathrm{N}$ rates (Experiment 1) and water managements (Experiment 2)

\begin{tabular}{llllll}
\hline & & $\mathrm{n}$ & Yield $\left(\mathrm{t} \mathrm{ha}^{-1}\right)$ & Head rice yield $(\%)$ & Nitrogen $(\%)$ \\
\hline Head rice yield & Experiment 1 & 27 & $0.601^{* * *}$ & & $0.573^{* *}$ \\
& Experiment 2 & 18 & $0.623^{* *}$ & & \\
Chalkiness & pool & 45 & $0.537^{* * *}$ & & $-0.494^{* *}$ \\
& Experiment 1 & 27 & $-0.386^{*}$ & $-0.222 \mathrm{~ns}$ & $-0.613^{* *}$ \\
& Experiment 2 & 18 & $-0.596^{* *}$ & $-0.295^{*}$ & \\
& pool & 45 & $-0.312^{*}$ & & \\
\hline
\end{tabular}

\section{Effect of Water Management on Yield and Milling Quality (Experiment 2)}

The rice varieties responded differently to the water treatments in the head rice yield and grain chalkiness, while their grain yield responded to both water management and variety (Table 2). The aerobic crop yielded on average $17 \%$ less than the wetland crop (Fig. 3). The wetland condition produced rice with better milling quality than the aerobic condition, except in 2 varieties (Fig. 4). Under wetland condition the rice varieties ranged in head rice yield from 41.5 to $52.8 \%$ and 3.0 to $17.0 \%$ in grain chalkiness. The head rice yield was lower and chalkiness percentage higher under aerobic condition than wetland condition in 7 out of the 9 varieties; exceptions were SPR3 and RD41 which showed little effect of water treatments in these measures of milling quality. The variety PTT1 suffered the largest depression in head rice yield as well as being among the varieties with the largest increase in grain chalkiness under aerobic compared with wetland culture. The relative chalkiness in the low, moderate and high chalkiness varieties from the $\mathrm{N}$ experiment were retained in the aerobic culture.

\section{Relationship Between Yield and Milling Quality}

The head rice yield and grain chalkiness were both yield dependent, but in different directions (Table 3). The head rice yield was positively correlated with grain yield, under both experiment 1 : $\mathrm{N}$ fertilizer $(\mathrm{r}=$ $0.601, \mathrm{p}<0.001)$ and experiment 2 : Water management $(\mathrm{r}=0.623, \mathrm{p}<0.01)$ (Table 3). On the other hand, chalkiness was negatively correlated with grain yield under both experiment 1: $\mathrm{N}$ fertilizer $(\mathrm{r}=-0.386$, $\mathrm{p}<0.05)$ and experiment 2 : water management $(\mathrm{r}=-$ $0.596, \mathrm{p}<0.01$ ) (Table 3). The negative correlation between head rice yield and chalkiness was found only in the experiment 2 : Water management $(\mathrm{r}=$ $0.613, \mathrm{p}<0.01)$, but not the experiment $2: \mathrm{N}$ fertilizer $(r=-0.222$, not significant at $p>0.05)$ (Table 3$)$.

\section{Discussion}

This study has demonstrated the interaction effect of genetics and environment $(\mathrm{G} \times \mathrm{E})$ on rice milling quality, as described by head rice yield and grain chalkiness. No discernable association was observed between the varieties' grain length (long grain vs. extra-long grain) or amylose content and their head rice yield and grain chalkiness.

\section{Effect of N Rates on Yield and Milling Quality}

Nitrogen fertilizer, routinely applied to increase yield in modern rice production (e.g., see GRiSP, 2013), has been shown here to improve milling quality of the rice grain while also increasing grain yield. That $\mathrm{N}$ fertilizer increases head rice yield by decreasing milling grain breakage is well established (Wopereis-Pura et al., 2002; Leesawatwong et al., 2005; Zhou et al., 2015). Resistance to milling breakage may be partly related to grain $\mathrm{N}$ concentration, as indicated by significant positive correlation between grain $\mathrm{N}$ and head rice yield $(\mathrm{r}=0.573, \mathrm{p}<0.01)$. However, the strong interaction effect of variety and nitrogen $(\mathrm{V} \times \mathrm{N}$, significant at $\mathrm{p}<0.001)$ was here defined by differences among the rice varieties (a) in the head rice yield when no $\mathrm{N}$ fertilizer was applied and (b) their varying responses to $\mathrm{N}$ fertilizer. With grain $\mathrm{N}$ at approximately $1 \%$ when no $\mathrm{N}$ fertilizer was applied, 6 out of 9 rice varieties in the present study already reached or exceeded the $40 \%$ head rice yield standard for price setting in the rough rice market in Thailand (Prom-u-Thai, 2010).

Chalkiness, the white opaque region in an otherwise translucent area of milled rice grain (Patindol and Wang, 2003), is considered an inferior quality characteristic of milled rice that affects rice price in most markets (Zhou et al., 2015). For example, chalkiness is among the stringently regulated criteria for differentiating the grades in each type of Thai rice (MoC, 2016), including the Thai $100 \% \mathrm{~B}$ rice used as a global benchmark. While $\mathrm{N}$ fertilizer application generally lowered grain chalkiness, chalkiness was only partially explained by grain $\mathrm{N}$ concentration $(\mathrm{r}=-0.494, \mathrm{p}<0.01)$, the groupings of rice varieties by their chalkiness were indistinguishable by their grain $\mathrm{N}$ at any level of $\mathrm{N}$ fertilizer. For example, without $\mathrm{N}$ fertilizer grain $\mathrm{N}$ was approximately $1 \%$ in all of the varieties but the chalkiness ranged from $5.7-11.7 \%$ in the low chalkiness group to $27.3-35.0 \%$ in the high chalkiness group and similarly when fertilized with $60 \mathrm{~kg} \mathrm{~N} \mathrm{ha}{ }^{-1}$. Increasing fertilizer to $120 \mathrm{~kg} \mathrm{~N} \mathrm{ha}^{-1}$ further increased the grain $\mathrm{N}$ in several varieties had little additional effect on 
reducing chalkiness, except in the variety PTT1. Chalkiness in rice grain occurs from loosely packed starch granules and protein bodies resulting in many air spaces in the starchy endosperm (Lisle et al., 2000), while starch synthesis, starch granule structure and arrangement of starch granules were suggested as other determinants (Ryoo et al., 2007). Differences in chalkiness among the rice varieties were not related in any way to their amylose content. Previous research suggested that chalkiness is caused by insufficient assimilation supply during grain development (Wang et al., 2007). Nitrogen stimulates photosynthesis and increases supply and translocation of assimilates to the grain during grain filling (Yoshida, 1981; Dobermann and Fairhurst 2000; Dordas 2009). The effect of $\mathrm{N}$ on photosynthate assimilation into the grain cannot explain the differential effects of grain $\mathrm{N}$ concentration as well as $\mathrm{N}$ fertilizer on grain chalkiness in the rice varieties that were tested. The inconsistant association between head rice yield and grain chalkiness, previously reported to vary with the growing season (Laenoi et al., 2018), was found here to be significant in the water experiment $(\mathrm{r}=-0.613, P<0.01)$ but not in the $\mathrm{N}$ experiment $(\mathrm{r}=-0.222$, not significant at $\mathrm{p}>0.05)$. The suggestion that the much easier to measure chalkiness could be used as a proxy for head rice yield in breeding programs (Zhou et al., 2015) is therefore questioned.

\section{Effect of Water Management on Yield and Milling Quality (Experiment 2)}

As others have reported (e.g., Bouman et al., 2005; Kato et al., 2009), this study has shown that aerobic culture produced lower yield than wetland culture. Some of these reports have also shown that the focus on aerobic rice is on efficiency of water use, that is the higher yield is produced per unit of water in aerobic culture although the yield per unit land may be lower. While these and other authors (e.g., Priyanka et al., 2012; Jana et al., 2016) have focused on how water use efficiency can be increased with aerobic rice, the effect on rice quality has received scarcely any attention. Three types of response to aerobic condition were identified among the rice varieties in their head rice yield, (a) the two varieties that were unaffected (SPR3 and RD41), (b) PTT1 with almost halved head rice yield and (c) the rest of the varieties that were moderately affected.

Stability of the low chalkiness trait that might be selected for is suggested by consistency in relative chalkiness of the rice varieties in aerobic and wetland culture and over different $\mathrm{N}$ levels, as well as much smaller variation in $\%$ chalkiness in the low chalkiness cultivars in varying $\mathrm{N}$ and water treatments. Difference in the head rice yield among the rice varieties, on the other hand, varied more with the environment, with different effects of grain $\mathrm{N}$ in different varieties. Resistance to milling breakage in spite of low grain $\mathrm{N}$ reported for KDML105, an aromatic rice variety with traditionally tall plant type (Leesawatwong et al., 2005) appears to have been incorporated into modern high yielding Thai rice varieties, which include the megavarieties PLS2, SPR1 and PTT1. However, it should be noted that postharvest management can play an important role in determining rice milling quality (Wongpornchai et al., 2004), by either over riding or improving on the effects of genotype, environment and management. Parboiling strengthens the rice grain against milling breakage as well as eliminates grain chalkiness, as the starch grains in the endosperm are fused together when the paddy is cooked before milling (Bhattacharya, 1969). Typically, one t of raw paddy is milled into $395 \mathrm{~kg}$ of head rice and $185 \mathrm{~kg}$ of broken rice, but one $\mathrm{t}$ of paddy that has been steamed in the parboiling process is milled into $580 \mathrm{~kg}$ of head rice and $70 \mathrm{~kg}$ of broken rice (Siamwalla and Na Ranong, 1990).

\section{Conclusion}

In conclusion, this study has demonstrated variation in the milling quality responses to $\mathrm{N}$ fertilizer and water management of modern, high yielding rice varieties with long and extra-long grain and amylose ranging from 15 to $30 \%$. While head rice yield generally increased with increasing grain $\mathrm{N}$, resistance to milling breakage at low grain $\mathrm{N}$ was found in several varieties. Stability of grain chalkiness against variation in the environment was indicated by relative chalkiness of the varieties regardless of the $\mathrm{N}$ and water treatments.

\section{Acknowledgement}

The authors would like to thank Thailand Research Fund for financial support. The first author is a recipient of a Royal Golden Jubilee PhD scholarship.

\section{Funding information}

This research was funded by Thailand Research Fund via Royal Golden Jubilee $\mathrm{PhD}$ scholarship (PHD/0348/2551).

\section{Conflicts of Interest}

The authors declare that there is no conflict of interest.

\section{References}

Bhattacharya, K.R., 1969. Breakage of rice during milling and effect of parboiling. Cereal Chem., 46: $478-485$.

Bhonsle, S.J. and K. Sellappa, 2010. Grain quality evaluation of traditionally cultivated rice varieties of Goa, India. Recent Res. Sci. Technol., 2: 88-97. 
Borrell, A.K., A.L. Garside, S. Fukai and D.J. Reid, 1999. Grain quality of flooded rice is affected by season, nitrogen rate and plant type. Aust. J. Agric. Res., 50: 1399-1408.

DOI: $10.1071 /$ AR98054

Bouman, B.A.M., S. Peng, A.R. Castañeda and R.M. Visperas, 2005. Yield and water use of irrigated tropical aerobic rice systems. Agric. Water Manage., 74: 87-105. DOI: 10.1016/j.agwat.2004.11.007

Dobermann, A. and T. Fairhurst, 2000. Rice: Nutrient disorders and nutrient management. Potash and Phosphate Institute, Potash and Phosphate Institute of Canada and International Rice Research Institute. Los Baños, Philippines.

Dordas, C., 2009. Dry matter, nitrogen and phosphorus accumulation, partitioning and remobilization as affected by $\mathrm{N}$ and $\mathrm{P}$ fertilization and source-sink relations. Eur. J. Agronomy, 30: 129-139.

DOI: 10.1016/j.eja.2008.09.001

Efferson, N.J., 1985. Rice Quality in World Markets. In: Rice Grain Quality and Marketing, Intern. Rice Research Institute, Manila, pp: 1-13.

FAO, 2012. Coping with water scarcity-an action framework for agriculture and food security (Water Reports No. 38). Food and Agriculture Organization of the United Nations. Rome, Italy.

GRiSP, 2013. Rice Almanac. 4th Edn., International Rice Research Institute, Los Baños.

Hayashi, M., K. Sugiura, C. Kuno, I. Endo and Y. Tanaka et al., 2011. Reduction of rice chalky grain by deep and permanent irrigation method; effect on growth and grain quality of rice. Plant Prod. Sci., 14: 282-290. DOI: 10.1626/pps.14.282

Jana, K., S.K. Das, G. Moinuddin, G.K. Mallick and B. Biswas, 2016. Grain yield of aerobic rice as influenced by seed rate and row spacing in aerobic situation under changed climate. J. Appl. and Nat. Sci., 8: 2164-2169. DOI: 10.31018/jans.v8i4.1106

Juliano, B.O., 1993. Rice in human nutrition. International Rice Research Institute and Food and Agriculture Organization of the United Nations. Rome.

Kato, Y., M. Okami and K. Katsura, 2009. Yield potential and water use efficiency of aerobic rice (Oryza sativa L.) in Japan. Field Crops Res., 113: 328-334. DOI: 10.1016/j.fcr.2009.06.010

Koutroubas, S.D., F. Mazzini, B. Pons and D.A. Ntanos, 2004. Grain quality variation and relationships with morpho-physiological traits in rice (Oryza sativa L.) genetic resources in Europe. Field Crops Res., 86: 115-130.

DOI: 10.1016/S0378-4290(03)00117-5

Laenoi, S., B. Rerkasem, S. Lordkaew and C. Prom-uThai, 2018. Seasonal variation in grain yield and quality in different rice varieties. Field Crops Res., 221: 350-357. DOI: 10.1016/j.fcr.2017.06.006
Leesawatwong, M., S. Jamjod, J. Kuo, B. Dell and B. Rerkasem, 2005. Nitrogen fertilizer increases seed protein and milling quality of rice. Cereal Chem., 82: 588-593. DOI:10.1094/CC-82-0588

Leesawatwong, M., S. Jamjod, B. Rerkasem and S. Pinjai, 2003. Determinants of a premium-priced, special-quality rice. Int. Rice Res. Notes, 28: 34.

Lisle, A.J., M. Martin and M.A. Fitzgerald, 2000. Chalky and translucent rice grains differ in starch composition and structure and cooking properties. Cereal Chem., 77: 627-632. DOI: 10.1094/CCHEM.2000.77.5.627

MoC, 2016. Ministry of Commerce Announcements on Standards for White Rice, Hom Rice and Hom Mali Rice (Royal Gazette Vol. 133 (special 243d)). Thailand Ministry of Commerce. Bangkok.

Patindol, J. and Y.J. Wang, 2003. Fine structures and physicochemical properties of starches from chalky and translucent rice kernels. J. Agric. Food Chem., 51: 2777-2784.

DOI: $10.1021 / \mathrm{jf0} 26101 \mathrm{t}$

Peng, S., B. Bouman, R.M. Visperas, A. Castañeda and H.K. Park, 2006. Comparison between aerobic and flooded Rice in the tropics: Agronomic performance in an eight-season experiment. Field Crop. Res., 96: 252-59. DOI: $10.1016 /$ j.fcr.2005.07.007

Perez, C.M., B.O. Juliano, S.P. Lisbon, J.M. Alcantara and K.G. Cassman, 1996. Effects of late nitrogen fertilizer application on head rice yield, protein content and grain quality of rice. Cereal Chem., 73: 556-560.

Priyanka, S., B. Jitesh and S. Babu, 2012. Aerobic rice, a new approach of rice cultivation. Int. J. Res. Biosci., 1: 1-6.

Prom-u-Thai, C., 2010. Case study 10: Rice quality evaluation. Agricultural Research for Local Solutions and Opportunities Project Thailand: Public Policy Studies Institute, Chiang Mai University, Chiang Mai.

Ryoo, N., C. Yu, C.S. Park, M.Y. Baik and I. Park et al., 2007. Knockout of a starch synthase gene OsSSIIIa causes white-core floury endosperm in rice (Oryza sativa L.). Plant Cell Rep., 26: 1083-1095.

DOI: 10.1007/s00299-007-0309-8

Sharma, S.K., Y.V. Singh, S. Tyagi and A. Bhatia, 2016. Influence of rice varieties, nitrogen management and planting methods on methane emission and water productivity. Paddy Water Environ., 14: 325-333. DOI: $10.1007 / \mathrm{s} 10333-015-0502-2$

Siamwalla, A. and V.N. Ranong, 1990. PramualKwamRooRuang Kao (Compilation of Knowledge on Rice). Thailand Development Research Institute. Bangkok. 
Wang, F., S. Chen, F. Cheng, Y. Liu and G. Zhang, 2007. The differences in grain weight and quality within a rice (Oryza sativa L.) panicle as affected by panicle type and source-sink relation. J. Agron. Crop Sci., 193: 63-73. DOI: 10.1111/j.1439-037X.2006.00244.X

Wang, Q., J. Huang, F. He, K. Cui and J. Zeng et al., 2012. Head rice yield of "super" hybrid rice Liangyoupeijiu grown under different nitrogen rates. Field Crops Res., 134: 71-79.

DOI: $10.1016 /$ j.fcr.2012.05.001

Wongpornchai, S., K. Dumri, S. Jongkaewwattana and B. Siri, 2004. Effects of drying methods and storage time on the aroma and milling quality of rice (Oryza sativa L.) cv. Khao Dawk Mali 105. Food Chem., 87: 407-414.

DOI: 10.1016/j.foodchem.2003.12.014

Wopereis-Pura, M.M., H. Watanabe, J. Moreira and M.C.S. Wopereis, 2002. Effect of late nitrogen application on rice yield, grain quality and profitability in the Senegal River valley. Eur. J. Agron., 17: 191-198. DOI:10.1016/S1161-0301(02)00009-6

Yoshida, S., D.A. Forno, J.H. Cock and K.A. Gomez, 1976. Laboratory Manual for Physiological Studies of Rice. 3rd Edn., The International Rice Research Institute. Los Baños, Laguna, Philippines.
Yoshida, S., 1981. Fundamental of rice crop science. The International Rice Research Institute. Los Baños. Laguna, Philippines.

Zhang, H., S. Zhang, J. Yang, J. Zhang and Z. Wang, 2008. Postanthesis moderate wetting drying improves both quality and quantity of rice yield. Agron. J., 100: 726-734. DOI: 10.2134 /agronj2007.0169

Zhao, X. and M. Fitzgerald, 2013. Climate change: implications for the yield of edible rice. PloS One, 8: e66218- e66218.

DOI: 10.1371/journal.pone.0066218

Zhou, L., S. Liang, K. Ponce, S. Marundon and G. Ye et al., 2015. Factors affecting head rice yield and chalkiness in indica rice. Field Crops Res., 172: 1-10. DOI: 10.1016/j.fcr.2014.12.004

Zhu, D.W., H.C. Zhang, B.W. Guo, K. Xu and Q.G. Dai et al., 2017. Effects of nitrogen level on yield and quality of japonica soft super rice. J. Integr. Agric., 16: 1018-1027.

DOI: $10.1016 / \mathrm{S} 2095-3119(16) 61577-0$ 